\title{
Comparison of Characteristics of the nodX Genes from Various Rhizobium leguminosarum Strains
}

\author{
Alexandra O. Ovtsyna, ${ }^{1,2}$ Geert-Jan Rademaker, ${ }^{3}$ Edwin Esser, ${ }^{3}$ Jeremy Weinman, ${ }^{4}$ Barry G. Rolfe,${ }^{4}$ \\ Igor A. Tikhonovich, ${ }^{2}$ Ben J. J. Lugtenberg, ${ }^{1}$ Jane E. Thomas-Oates, ${ }^{3}$ and Herman P. Spaink ${ }^{1}$ \\ ${ }^{1}$ Institute of Molecular Plant Sciences, Clusius Laboratory, Leiden University, Wassenaarseweg 64, $2333 \mathrm{AL}$ \\ Leiden, The Netherlands; ${ }^{2}$ All-Russia Research Institute for Agricultural Microbiology, Podbelsky shosee \\ 3, 189620 St. Petersburg, Pushkin 8, Russia; ${ }^{3}$ Department of Mass Spectrometry, Bijvoet Center \\ for Biomolecular Research, Utrecht University, Sorbonnelaan 16, 3584 CA Utrecht, The Netherlands; \\ ${ }^{4} \mathrm{PMI}$ Group, Research School of Biological Sciences, Australian National University, GPO Box 475, \\ Canberra ACT 2601, Australia \\ Accepted 5 December 1998.
}

\begin{abstract}
We have analyzed the nucleotide sequences of the $\operatorname{nodX}$ genes from two strains of Rhizobium leguminosarum bv. viciae able to nodulate Afghan peas (strains A1 and Himalaya) and from two strains of $R$. leguminosarum bv. trifolii (ANU843 and CSF). The nodX genes of strains A1 and ANU843 were shown to be functional for the induction of nodules on Afghan peas. To analyze the cause of phenotypic differences of strain A1 and strain TOM we have studied the composition of the lipochitin-oligosaccharides (LCOs) produced by strain A1 after induction by the flavonoid naringenin or various pea root exudates. The structural analysis of the LCOs by mass spectrometry revealed that strain A1 synthesizes a family of at least 23 different LCOs. The use of exudates instead of naringenin resulted only in quantitative differences in the ratios of various LCOs produced.
\end{abstract}

Most wild-type pea cultivars from Afghanistan are resistant to nodulation by European and North American Rhizobium strains due to the presence of the single genetic locus $s y m 2^{A}$ (Kozik et al. 1995; Lie 1978). R. leguminosarum bv. viciae strains able to overcome this resistance were initially isolated from soils in the Middle East (Winarno and Lie 1979) and later from other regions of the world (Ma and Iyer 1990). It was shown by Southern hybridization (Ma and Iyer 1990) that all these strains carry an additional gene, designated nodX, that was first described in strain TOM (Davis et al. 1988). By

Corresponding author: Herman P. Spaink, Institute of Molecular Plant Sciences, Clusius Laboratory, Leiden University, Wassenaarseweg 64, 2333 AL Leiden, The Netherlands; Telephone: +31-71-5275055, Fax: +31-71-5275088, E-mail: spaink@ rulbim.LeidenUniv.nl

Current address Jane E. Thomas-Oates: Michael Barber Centre for Mass Spectrometry, Department of Chemistry, U.M.I.S.T., P.O. Box 88, Manchester, M60 1QD, U.K.

Nucleotide and/or amino acid sequence date have been deposited in the GenBank data base as accession numbers AF031146, AF084223, and AF084224. functional complementation the presence of a $\operatorname{nodX}$ gene was also predicted in $R$. leguminosarum bv. trifolii strains but its function in this biovar was unknown (Lewis-Henderson and Djordjevic 1991b; Canter Cremers et al. 1988). There is evidence that the nodX gene from the $R$. leguminosarum bv. viciae strain TOM encodes an $O$-acetyl transferase that transfers an acetyl group to the reducing terminal residue of lipochitinoligosaccharides (LCOs) produced by rhizobia (Firmin et al. 1993). The LCOs, also called Nod factors, are the bacterial signal molecules produced in response to secretion of flavonoids by the host plants. These flavonoids activate the transcription of the bacterial genes (called nod, nol, or noe genes) that are involved in the synthesis of the Nod factors. The modifications present on the LCO core structure are important determinants of the host specificity in rhizobia-legume symbioses (for reviews see Bladergroen and Spaink 1998; Dénarié et al. 1996). The finding that the rhizobial nodX gene controls the O-acetylation of the reducing terminal residue of LCOs suggests that $\operatorname{sym} 2^{A}$-carrying peas require rhizobial strains producing doubly acetylated Nod factors for nodulation. Although a large collection of $R$. leguminosarum strains nodulating Afghan peas has been described (Ma and Iyer 1990), all the data on the genetic and biochemical control of the host specificity of symbiosis with $s y m 2^{A}$-carrying peas strains were obtained only from the study of the $\operatorname{nodX}$ gene from $R$. leguminosarum bv. viciae TOM (Winarno and Lie 1979).

The aim of this work was to compare the characteristics of the $\operatorname{nodX}$ genes present in different wild-type $R$. leguminosarum strains with the homologous nodX gene from $R$. leguminosarum bv. viciae TOM, whose sequence and function have been described (Firmin et al. 1993; Davis et al. 1988). We have analyzed two other $R$. leguminosarum bv. viciae strains, A1 (Chetkova and Tikhonovich 1986) and Himalaya (Lie 1981), and two R. leguminosarum bv. trifolii strains, ANU843 (Rolfe et al. 1985) and CSF. Strain A1 was isolated from soils of northwestern Russia based on its ability to elicit nodules on Afghan peas and its high competitive ability in coinoculation experiments. Nodulation by strain A1, in contrast to that by strain TOM, is not inhibited by various $R$. legumi- 
nosarum strains that do not contain the nodX gene, a phenomenon called "competitive nodulation blocking" (Dowling et al. 1987; Chetkova and Tikhonovich 1986).

The nodX genes from strains A1, Himalaya, and CSF were cloned following PCR (polymerase chain reaction) amplification of bacterial genomic DNA with specific primers for the $\operatorname{nodX}$ gene based on the nodX sequence from $R$. leguminosarum bv. viciae TOM described earlier (Davis et al. 1988). The sequence from the strain ANU843 nodX gene was determined by sequencing 1,946 nucleotides (nt) downstream of a point within the $\operatorname{nodN}$ gene located on plasmid pJJ258 (Table 1). The data show that the $\operatorname{nodX}$ gene is positioned $284 \mathrm{nt}$ downstream of nodN (Lewis-Henderson and Djordjevic 1991b). The nucleotide sequences of the cloned fragments were determined completely in the case of the nodX genes from strains A1 and ANU843, or partially in the case of strains Himalaya and CSF. The ANU843 and CSF sequences have been deposited in the GenBank data base (accession numbers AF031146, AF084223 and AF084224). The nodX genes appear to be very similar to each other and to the known nodX sequence of strain TOM. The closest similarity was observed within $R$. leguminosarum bv. viciae since the complete coding sequence of the nodX gene from strain A1 differed from that of strain TOM in only 3 nucleotide residues (listed in the legend to Figure 1). This result was confirmed by sequencing a clone derived from independently isolated chromosomal DNA. Surprisingly, the sequenced part of the nodX gene from strain Himalaya (600 out of $1,101 \mathrm{bp}$ ) did not display any differences with the homologous part of the nodX gene from strain A1. The nodX genes from the R. leguminosarum bv. trifolii strain ANU843 were $94 \%$ homologous to those of strain TOM (71 bp different in the coding region of 1,104 bp). As shown in Figure 1, the degree of similarity was somewhat higher at the level of the predicted amino acid sequence, where only 23 amino acids are different between the predicted NodX proteins of strains ANU843 and TOM. Interestingly, the sequence of the nodX homologue of strain CSF shows a replacement of leucine 41 by a stop codon and also a frame shift in the middle of the gene (Fig. 1), indicating that this nodX gene is not functional and is maintained in the genome as a degenerate copy.

To test the function of the cloned nodX genes from $R$. leguminosarum bv. trifolii ANU843 and from R. leguminosarum bv. viciae A1, we tested their capacity to confer on $R$. leguminosarum bv. viciae 248 the ability to nodulate Afghan peas. For expression of the cloned nodX genes in rhizobia, we have re-cloned them under the control of the nodABCIJ promoter into a broad-host-range plasmid. The resulting nodX-carrying plasmids pMP3219 and pJJ392 (containing nodX from strains A1 and ANU843, respectively) were introduced into strain 248 , which lacks the nodX gene, and the resulting transconjugant strains were used for inoculation of wild-type Afghan pea line L2150. For inoculation of line L2150, use was made of the gravel test system as described previously (Ovtsyna et al. 1998). For each experiment 12 plants were analyzed and nodulation was scored after 6 weeks.

The results showed that both $\operatorname{nodX}$ genes confer the ability to nodulate Afghan pea as efficiently as the positive control

Table 1. Bacterial strains and plasmids used in this study

\begin{tabular}{|c|c|c|}
\hline Strain or plasmid & Relevant characteristics & Source or reference \\
\hline \multicolumn{3}{|l|}{ Strains ${ }^{\mathrm{a}}$} \\
\hline 248 & Rhizobium leguminosarum bv. viciae wild type & Josey et al. 1979 \\
\hline A1 & $\begin{array}{l}\text { R. leguminosarum bv. viciae wild-type strain nodulating on Afghan peas, isolated from } \\
\text { soils of northwestern Russia }\end{array}$ & Chetkova and Tikhonovich 1986 \\
\hline TOM & $\begin{array}{l}\text { R. leguminosarum bv. viciae wild-type strain nodulating on Afghan peas, isolated in } \\
\text { Turkey }\end{array}$ & Lie 1978 \\
\hline ANU843 & R. leguminosarum bv. trifolii wild-type strain & Rolfe et al. 1985 \\
\hline Himalaya & $\begin{array}{l}\text { R. leguminosarum bv. viciae wild-type strain nodulating on Afghan peas, isolated from a } \\
\text { nodule of Vicia faba growing in the Hindukush region }\end{array}$ & Lie 1981 \\
\hline CSF & R. leguminosarum bv. trifolii wild-type strain isolated from nodules of Trifolium pratense & This work \\
\hline \multicolumn{3}{|c|}{ 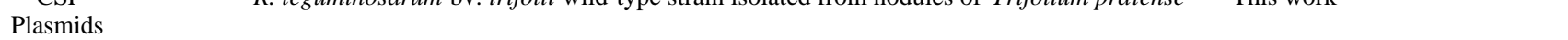 } \\
\hline pRL1JI & Sym plasmid of the $R$. leguminosarum bv. viciae strain 248 & Johnston et al. 1978 \\
\hline pRK2013 & IncColE1, $\mathrm{Tra}^{+}, \mathrm{Km}^{\mathrm{r}}$ & Ditta et al. 1980 \\
\hline pET3d & IncColE1, expression vector based on the bacteriophage $\mathrm{T} 7$ promoter, $\mathrm{Amp}^{\mathrm{r}}$ & Studier et al. 1990 \\
\hline pIC20R & IncColE1, cloning vector, $\mathrm{Amp}^{\mathrm{r}}$ & Marsh et al. 1984 \\
\hline pGEM-5Z(+) & IncColE1, cloning vector, Amp ${ }^{r}$ & Promega, Madison, WI \\
\hline mp8 & Bacteriophage M13-derived cloning vector & Messing and Vieira 1982 \\
\hline pMP3510 & IncP, multiply cloning vector containing nodABCIJ promoter, $\mathrm{Tc}^{\mathrm{r}}$ & Spaink et al. 1995b \\
\hline pWB5a & IncP, multicopy cloning vector, $\mathrm{Tc}^{\mathrm{r}}$ & Hirsch et al. 1985 \\
\hline pMP3218 & $\begin{array}{l}\text { Plasmid pET3d containing the nodX gene of strain A1 under control of the } \mathrm{T} 7 \text { promoter, } \\
\text { Amp }^{\mathrm{r}}\end{array}$ & This work \\
\hline pMP3219 & $\begin{array}{l}\text { Plasmid pMP3510 containing the nodX gene of strain A1 under control of the NodABCIJ } \\
\text { promoter, } \mathrm{Tc}^{\mathrm{r}}, \mathrm{Amp}^{\mathrm{r}}\end{array}$ & This work \\
\hline pJJ258 & $\begin{array}{l}\text { Plasmid pBluescript SK(+) carrying a 3-kb BglII-BamHI fragment (present in pRT290) } \\
\text { containing a partial nodM gene, and the } \operatorname{nodN} \text { and nodX genes from strain ANU843 }\end{array}$ & $\begin{array}{l}\text { This work and Djordjevic et al. } \\
1986\end{array}$ \\
\hline pJJ390 & $\begin{array}{l}\text { Plasmid pWB5a carrying the strain ANU843 NodABCIJ promoter as a 242-bp fragment }{ }^{\text {b }} \\
\text { in the BamHI site of the polylinker, Inc-P, } \text { Tc }^{\mathrm{r}}\end{array}$ & This work \\
\hline pJJ392 & $\begin{array}{l}\text { Plasmid pJJ390 carrying the strain ANU843 nodX gene as a PstI-XbaI fragment from } \\
\text { pJJ258, Tc }\end{array}$ & This work \\
\hline
\end{tabular}

${ }^{\mathrm{a}}$ Rhizobial strains were gron in $\mathrm{B}^{-}$medium supplemented with phosphate buffer (100 mg/ml; van Brussel et al. 1977).

${ }^{\mathrm{b}}$ This fragment was first isolated as a 242-bp BamHI-BglII cartridge by amplification with the proof-reading Deep Vent DNA polymerase (New England Biolabs, Hertfordshire, U.K.) and the oligonucleotide primers 5'-CCAGGATCCATGCAAAGCTCCAA-3' (located in complementary sequence of nodA) and 5'-CTTAGATCTCATTCTCGATCCAC-3' (located in sequence of nodD). 
strain TOM. As judged by the dry weight of the plants after 6 weeks of growth, the nodules apparently also fixed nitrogen efficiently. Under the test conditions used, strain 248 was completely unable to induce nodules on Afghan pea plants. In conclusion, the introduction of the separate nodX gene from strains ANU843 and A1 was sufficient to confer on strain 248 the ability to elicit effective nodules on Afghan peas.

We have studied whether the presence of the nodX gene in $R$. leguminosarum bv. viciae A1 correlates with the production of doubly acetylated LCOs, as was shown for strain TOM
(Firmin et al. 1993). First, the ability of strain A1 to produce Nod factors was studied by means of thin layer chromatography (TLC). Cells of strain A1 were grown with $\left[1-{ }^{14} \mathrm{C}\right]-\mathrm{D}-$ glucosamine in the presence of the appropriate inducer. The culture fluids were extracted into $n$-butanol, concentrated, and applied to reverse-phase TLC plates by published methods (Spaink et al. 1994b). The results show that, with several commercial inducers and root exudates from different pea lines (lines L32, L1887, and L6559), strain A1 produces LCOs in much larger quantities than does strain TOM, and

$\begin{array}{lllll} & 1 & & & \\ \text { A1 } & \text { MGPSNEHSSG } & \text { HRNNFDLLRL FAACQVMFSH } & \text { AWNWLHLGDP LNGTWVEDLL } \\ \text { ANU843 } & \text { MGPSNEHSSG HRNNFDLLRL FAACQVMFSH AWNWLHLGDS LNGTAAFNLL }\end{array}$

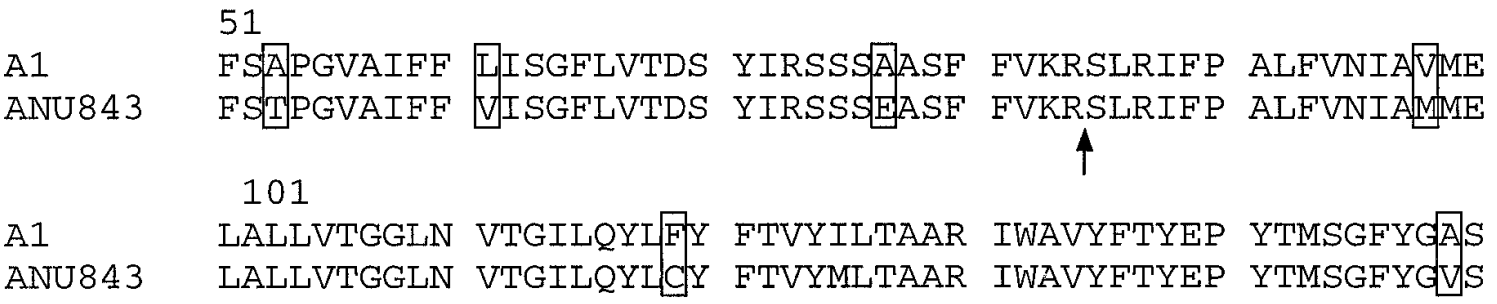

A1 151 DPSGVLWTLT VELTFYLTLP MLLEIWRRWK RAGALVVAVA ALGSWVMAOH ANU843 DPSGVLWTLT VELTFYLTLP TLLEIWRRWK RAGALVVAVA ALGSWVMAQY

201

A1 FNITD RYNPC LSVTAGPTFW IFSMGVLARL YWHRVSRIFE GKLLWWLATH ANU843 FNITDRYNPF LSVTUGPTFW IFSMGVLARL YWHRVSRIFE GKLLWWLAA A

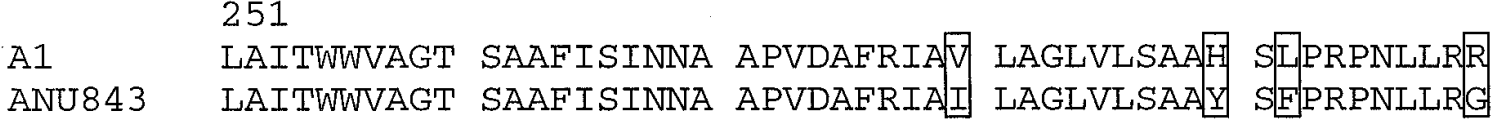

301

A1 QDLSYGIYLY HMLVMHTLIA IGWVGHWWLW IVEPVGTVAL AALSWALIEQ

ANU843 QDLSYGIYLY HMLVMHTLIG MGWVGHWWLW IVEPVGTVAL AALSWALIEK

$\begin{array}{lll} & 351 & 368 \\ \text { A1 } & \text { PAMKLRTSLV } & \text { ARRLSVA } \\ \text { ANU843 } & \text { PAMKLRTSLV } & \text { ARRLSVA }\end{array}$

Fig. 1. Comparison of the protein sequences encoded by the nodX genes from the Rhizobium leguminosarum bv. viciae strain A1 and the R. leguminosarum bv. trifolii strain ANU843. Differences between the NodX sequence from strain A1 and the previously published sequence from strain TOM (Davis et al. 1988) are boxed, or underlined when the difference does not lead to a difference in the amino acid encoded. Differences found with the GenBank submission for nodX of strain TOM (X07990) are as follows: T conversion to C (position 353); T conversion to C (position 460); $\mathrm{T}$ conversion to G (position 960). The boxed leucine in the predicted NodX sequence of strain ANU843 indicates the position where a stop codon occurs in the sequence obtained from strain CSF, whereas an arrow indicates the position of a frame-shift mutation. The nodX genes from strains A1, Himalaya, and CSF were cloned by PCR (polymerase chain reaction). Specific primers for the nodX gene were designed according to the DNA sequence of the nodJ-nodX-containing region of strain TOM (Davis et al. 1988): upstream primer, oMP199 (5'-CCATGGGACCATCCAATGAAC-3') and downstream primer, oMP196 (5'-TTAAGCGACGGAAAGCCTTC-3') (Isogen Bioscience, Maarssen, The Netherlands). The DNA sequence amplified with these primers covered the structural part of the $\operatorname{nodX}$ gene, $1.1 \mathrm{~kb}$ in size. Amplification was performed with the high-fidelity enzyme Pwo DNA Polymerase (Boehringer, Mannheim, Germany) for 25 cycles in a RoboCycler PCR machine (Stratagene, La Jolla, CA). The amplified 1.1-kb DNA fragment was then purified and amplified for an additional 7 cycles with AmpliTaq Polymerase (Sigma Chemical, St. Louis, MO) to facilitate cloning of the PCR product into a pGEM T-vector (with linearized pGEM-5Z(+) vector with single-strand thymidines on the $3^{\prime}$ ends obtained from Promega, Madison, WI). Cloned genes were sequenced in the T-vector by the dideoxy chain termination method (Sanger et al. 1977). To determine the whole sequence of the nodX gene, AccI and Narl fragments of this gene were subcloned into M13mp8 and pIC20 ${ }^{\mathrm{r}}$ cloning vectors, respectively. Plasmid containing nodX fragments with deletions resulting from digestion of the T-vector-nodX plasmid with AccI, ApaI, and NarI endonucleases followed by re-circularization of the plasmid were also used for sequencing. 
comparable with those of standard $R$. leguminosarum bv. viciae 248, as judged by quantitation of the radioactive spots corresponding to LCOs (data not shown). Of the commercial inducers, the best was naringenin at a concentration of $3 \mu \mathrm{M}$, but the best LCO production was achieved when root exudates from European pea line L32 were used for induction.

Based on these results, LCOs produced by $R$. leguminosarum bv. viciae A1 were obtained from 2-liter cultures grown in the presence of the inducers naringenin or pea root exudate. Root exudates from European pea line L32 and from Afghan pea line L6559 were chosen as the best inducers on the basis of the labeling experiments. As a control, LCOs were purified from 2-liter cultures of $R$. leguminosarum bv. viciae 248 induced by naringenin. LCOs were extracted into $n$-butanol and purified by reverse-phase HPLC (high-pressure liquid chromatography) as described previously (Spaink et al. 1995a). The HPLC profiles of LCOs induced by naringenin in strain A1 and in strain 248 are shown in Figure 2. The HPLC profiles of LCOs derived from these strains are very similar except that at least one additional peak was present in the HPLC profile of strain A1, eluting with a retention time of 35 min (Fig. 2B). Diode array analysis showed that this peak has a specific absorbance maximum at $304 \mathrm{~nm}$ (data not shown). HPLC profiles of LCOs induced by root exudates of European and Afghan pea lines in strain A1 were indistinguishable except for a quantitative difference in the relative intensity of the peak at $34 \mathrm{~min}$ (Fig. 2C and D). More obvious differences were observed with the naringenin-induced culture in the relative intensities of the different peaks. The additional peak observed in the LCO pattern from strain A1, compared with that from strain 248 , migrates at a position similar to that for the doubly acetylated, pentasaccharide Nod factors characteristic of $R$. leguminosarum bv. viciae TOM (Firmin et al. 1993). For analysis of the LCO molecular structures, separate fractions were collected after HPLC (one sample per minute).
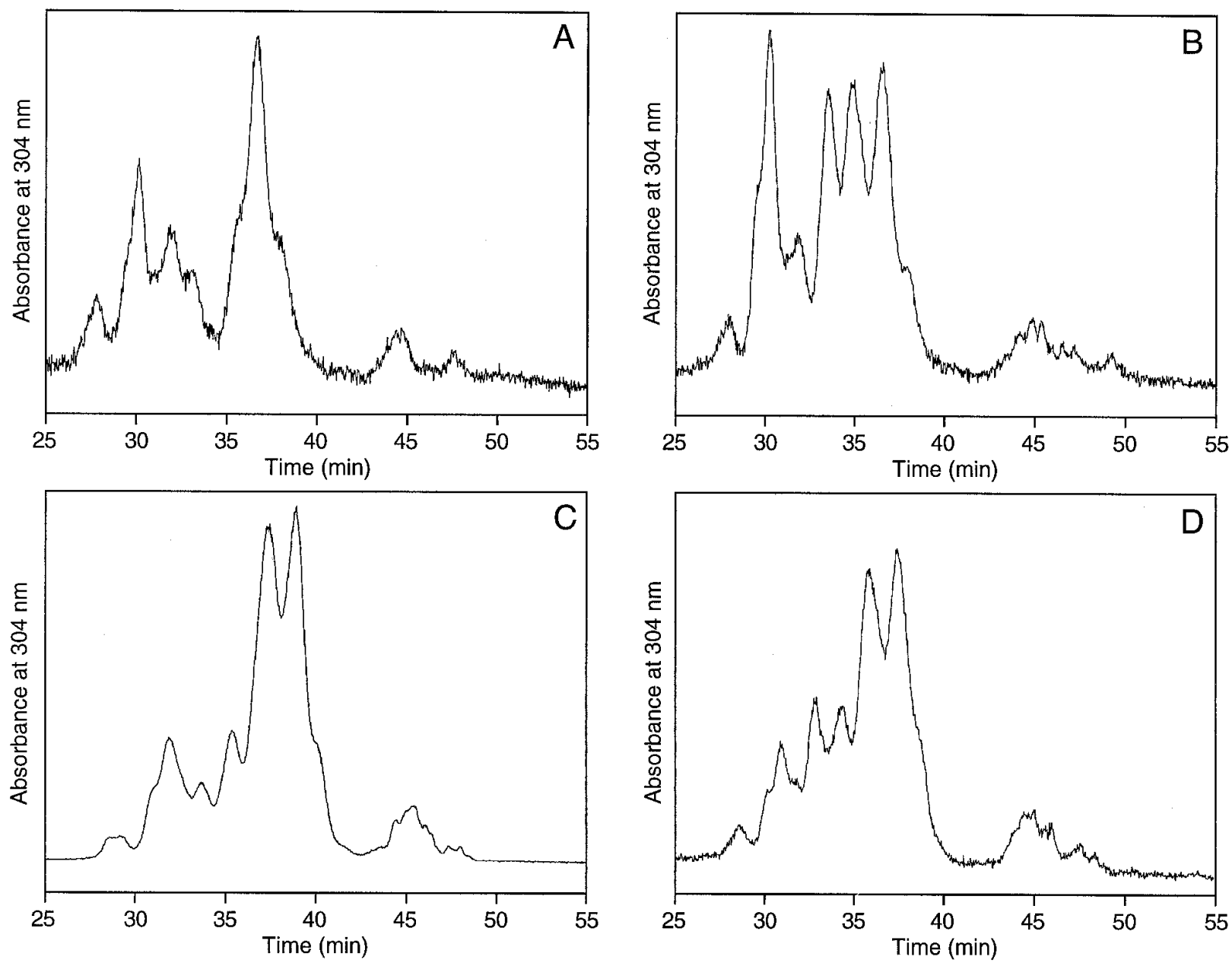

Fig. 2. HPLC (high-pressure liquid chromatography) profiles of Nod metabolites produced by the Rhizobium leguminosarum bv. viciae strains 248 and A1 induced by naringenin or pea root exudates. A, Strain 248 induced with naringenin. B, Strain A1 induced with naringenin. C, Strain A1 induced with European pea exudate. D, Strain A1 induced with Afghan pea (line L6559) exudate. For the preparation of exudates, pea seeds (50 per each line) were surface sterilized with concentrated sulfuric acid, washed thoroughly with sterile water, and germinated on minimal agar plates for 3 days. Then, seeds were transferred to filter paper in petri dishes with water for the secretion of the exudates. After 3 days the exudates were collected, seeds and filter paper were washed with water, and these solutions were pooled. The exudates were purified by filtering through Whatman no. 1 filter paper, evaporated under vacuum, and dissolved in $3 \mathrm{ml}$ of $30 \%$ ethanol (1/10 of the initial volume) and used in a 1:500 dilution. Separation of lipochitin-oligosaccharides (LCOs) was carried out on a reverse-phase column $(5 \mathrm{~mm}, 4 \times 250 \mathrm{~mm}$; Pharmacia LKB, Uppsala, Sweden) with a gradient running from $30 / 70$ acetonitril/water to pure acetonitril at a flow rate of $0.7 \mathrm{ml} / \mathrm{min}$. 
The structures of the Nod factors produced by strain A1 were determined by fast atom bombardment (FAB) mass spectrometry and collision-induced dissociation (CID) tandem mass spectrometry. It was shown that strain A1 produces a large variety of LCOs (Table 2). As expected, the additional peak present in the LCO profile from strain A1 (at 35 min retention time) correlates with the presence of doubly acetylated, pentasaccharidic LCOs. In addition to these Nod factors, several species were found to be produced by A1 that were not reported from the previously analyzed $R$. leguminosarum bv. viciae strains, namely LCOs with C18:2 and C18:3 fatty acids (Table 2; Spaink et al. 1994a). Qualitative variations in the LCOs produced when different inducers were used were not detectable. However, considering the mass spectrometric data alongside the HPLC chromatograms (for simplicity only shown at $304 \mathrm{~nm}$ absorbance in Figure 2), it is evident that there are two quantitative differences between the LCOs induced by naringenin and those induced by root exudates: (i) naringenin-induced bacteria produce relatively very little of the trisaccharidic species, whereas the bacteria induced by root exudates produce more abundant trisaccharidic LCOs; and (ii) in naringenin-induced bacteria more pentasaccharidic LCOs were detected than in exudate-induced fractions, where tetrasaccharides were the major products de- tected. In summary, pea root exudates induce abundant synthesis of short (3 to 4 monosaccharide residue) LCOs, while in naringenin-induced fractions the LCOs with longer backbones were observed in relatively large amounts.

To conclude, strain A1 produces a wide spectrum of Nod factors, including the doubly acetylated species reported previously from strain TOM (Firmin et al. 1993), and additional LCO species that are not commonly observed from the $R$. leguminosarum bv. viciae strains analyzed previously (Spaink et al. 1995b). It can also be noted, that under optimal conditions of induction, strain A1 was able to produce large total amounts of LCOs, typically of the order of 1 to $10 \mathrm{mg}$ per liter. In contrast, it was reported that strain TOM produces only minor quantities of LCOs (Firmin et al. 1993), a result that was confirmed by some preliminary experiments in our laboratory (data not shown).

The presence of the nodX gene was also predicted for some $R$. leguminosarum bv. trifolii strains (Lewis-Henderson and Djordjevic 1991a; Ma and Iyer 1990). However, the presumed location of the nodX gene in $R$. leguminosarum bv. trifolii was shown to be different from that in $R$. leguminosarum bv. viciae, since in $R$. leguminosarum bv. trifolii hybridization was observed downstream of the nodN gene. The functional ability of the $\operatorname{nodX}$ gene from strain ANU843 was tested by intro-

Table 2. Lipochitin-oligosaccharides (LOCs) produced by the Rhizobium leguminosarum bv. viciae strain A1 in the presence of different inducers ${ }^{\mathrm{a}}$

\begin{tabular}{|c|c|c|c|c|c|}
\hline \multirow[b]{3}{*}{ LCO structure } & & & \multicolumn{3}{|c|}{ Retention time (min) } \\
\hline & \multicolumn{2}{|c|}{ Mass spectrometric data $m / z^{b}$} & \multicolumn{3}{|c|}{ Induction gene-inducing factor } \\
\hline & $\mathbf{M}+\mathbf{H}^{+}$ & MS-MS fragment ions & Naringenin & Afghan pea & European pea \\
\hline III $(18: 1, \mathrm{Ac})$ & 892 & 468,671 (EP, AP) & $45-46$ & $39-46.5$ & $43-49$ \\
\hline III (18:2, Ac) & 890 & & 45 & $39-44.5$ & $43-46$ \\
\hline IV $(16: 0, A c)$ & 1069 & & $37-40$ & $38-42$ & $36-43$ \\
\hline IV $(16: 1, \mathrm{Ac})$ & 1067 & & $33-34$ & $33-38$ & $33-37$ \\
\hline IV $(18: 0, \mathrm{Ac})$ & 1097 & & $\mathrm{NC}$ & $\mathrm{NC}$ & $51-52$ \\
\hline IV $(18: 1)$ & 1053 & & $37-42$ & $38-46.5$ & $40-43$ \\
\hline IV $(18: 1, A c)$ & 1095 & & $42-46$ & $43-46.5$ & $43-51$ \\
\hline IV $(18: 1-\mathrm{OH}, \mathrm{Ac})$ & 1111 & $484,687,890(\mathrm{AP})$ & $32-35$ & $34-38$ & $35-38$ \\
\hline IV $(18: 2, \mathrm{Ac})$ & 1093 & & $34-40+42-43$ & $30-35+43$ & $30-33,35-36+40-44$ \\
\hline IV $(18: 3, \mathrm{Ac})$ & 1091 & & $31+33-40$ & $30-35+39-43$ & $30-36+40-43$ \\
\hline IV $(18: 4, \mathrm{Ac})$ & 1089 & & $32-33+35-38$ & $33-39$ & $33-40$ \\
\hline $\mathrm{V}(16: 0, \mathrm{Ac})$ & 1272 & & $31-37$ & $32-39$ & $31-41$ \\
\hline $\mathrm{V}(16: 0, \mathrm{Ac} 2)$ & 1314 & $442,645,848,1051(\mathrm{AP})$ & $37-38$ & $36-43$ & $38-43$ \\
\hline $\mathrm{V}(18: 0, \mathrm{Ac} 2)$ & 1342 & $470,673,876,1079$ (ЕP) & $\mathrm{NC}$ & $\mathrm{NC}$ & $50-52$ \\
\hline $\mathrm{V}(18: 1)$ & 1256 & & $31-34$ & $33-35$ & $33-36$ \\
\hline $\mathrm{V}(18: 1, \mathrm{Ac})$ & 1298 & & $37-46$ & $36-46.5$ & $38-49$ \\
\hline $\mathrm{V}(18: 1-\mathrm{OH}, \mathrm{Ac})$ & 1314 & & $29-32$ & $30-32$ & $30-32$ \\
\hline $\mathrm{V}(18: 1, \mathrm{Ac} 2)$ & 1340 & $468,671,874,1077$ (ЕP) & $44-45$ & $43-46.5$ & $45-50$ \\
\hline $\mathrm{V}(18: 2, \mathrm{Ac})$ & 1296 & & $34-35$ & $34-38$ & $34-36$ \\
\hline $\mathrm{V}(18: 3, \mathrm{Ac})$ & 1294 & & $32-34$ & $33-35$ & $34-36$ \\
\hline $\mathrm{V}(18: 3, \mathrm{Ac} 2)$ & 1336 & Insufficient for MS-MS & 38 & $38-42$ & $38-41$ \\
\hline $\mathrm{V}(18: 4, \mathrm{Ac})$ & 1292 & $462,665,868,1071(\mathrm{EP})$ & $29-33$ & $30-33$ & $29-38$ \\
\hline $\mathrm{V}(18: 4, \mathrm{Ac} 2)$ & 1334 & $462,665,868,1071(\mathrm{EP}, \mathrm{AP})$ & $33-35$ & $32-38$ & $33-38$ \\
\hline
\end{tabular}

a Abbreviations: $\mathrm{EP}=$ data obtained only from European pea exudate; $\mathrm{AP}=$ data obtained only from Afghan pea exudate; $\mathrm{NC}=$ not collected; $\mathrm{MS}=$ mass spectrometry.

${ }^{\mathrm{b}}$ Positive-ion mode FAB (fast atom bombardment) mass spectra were obtained with MS1 of a JEOL JMS-SX/SX102A tandem mass spectrometer operated at $10 \mathrm{kV}$ accelerating voltage. The FAB gun was operated at $6 \mathrm{kV}$ accelerating voltage with an emission current of $10 \mathrm{~mA}$ and xenon as the bombarding gas. Spectra were scanned at a speed of $30 \mathrm{~s}$ for the full mass range specified by the accelerating voltage used, and were recorded and averaged on a Hewlett Packard HP9000 data system running JEOL Complement software. CID (collision-induced dissociation) mass spectra were recorded with the same machine, with nitrogen as the collision gas in the third FFR collision cell, at a pressure sufficient to reduce the parent ion to one third of its original intensity. Monothioglycerol was used as the matrix, unless noted otherwise, when meta-nitrobenzylalcohol $(m-\mathrm{NBA})$ was used. The HPLC (high-pressure liquid chromatography) fractions were dried and redissolved in $10 \mu \mathrm{l}$ of dimethyl sulphoxide prior to mass spectrometric analysis. From each of the fractions a 1- to 3- $\mu \mathrm{l}$ aliquot was loaded into the matrix. The matrix used was thioglycerol for most FAB-MS spectra and all CID-MSMS spectra. In some cases $m$ NBA containing a large amount of sodium was used for the FAB mass spectra. When the spectra run in $m$ NBA were compared with those run in thioglycerol the relevant LCO signals were shifted $22 \mathrm{amu}$, corresponding to the formation of $[\mathrm{M}+\mathrm{Na}]^{+}$rather than $[\mathrm{M}+\mathrm{H}]^{+}$pseudomolecular ions, thus facilitating the correct assignment of the structures. When $m$ NBA was used as the matrix, the sensitivity of the analysis was significantly reduced. 
duction of the cloned gene into $R$. leguminosarum bv. viciae strain 248, which is not able to nodulate Afghan peas. The results show that the introduction of the separate nodX gene from strain ANU843 was sufficient to confer on strain 248 the ability to elicit effective nodules on Afghan peas. In agreement with these results is the finding that some classes of LCOs produced by the wild-type strain ANU843 do contain a second $O$-acetyl group attached to $\mathrm{C} 6$ of the reducing terminal saccharide (Philip-Hollingsworth et al. 1995; M. Olsthoorn, J. E. Thomas-Oates, and H. P. Spaink, in preparation).

Our data on the structures of the Nod factors of strain A1 are in complete agreement with the data of Firmin et al. (Firmin et al. 1993) that indicate that the O-acetylation directed by the NodX protein is confined to LCO molecules of pentasaccharidic chain length. Phenotypic differences between these strains, such as the insensitivity of strain A1 to "competitive nodulation blocking" can therefore not be assigned to the presence of the second acetyl group in the LCOs. The difference in susceptibility to blocking by other strains could be explained in two obvious ways. First, the difference could be due to differences in the production of NodXindependent minor LCO species produced by strain A1. Considering the technical impossibility of purifying these minor LCOs species this hypothesis would be very difficult to test. Second, the difference could be due to the seemingly large difference in the quantities of LCOs produced by strains TOM and A1 under laboratory conditions. We have shown that strain A1 also produces relatively high levels of LCOs in the presence of pea exudates, indicating a possible biological role for the production of higher levels of Nod factors. Therefore, future studies on the differences between strains A1 and TOM in symbiosis and competitiveness could be directed at determining whether there are differences in the regulation of the level of Nod factor production under laboratory and field conditions.

\section{ACKNOWLEDGMENTS}

This work was supported by the Netherlands Organization for Scientific Research (NWO-Pionier grant to H. P. S.), INTAS (project no. 94-.1058 to B. J. J. L.), and the European Union (TMR no. ERB4061PL970121 to H. P. S.). We thank C. T. Vernooy-van Dam (Utrecht University) and Peter Hock (Leiden University) for assistance with the preparation of the tables and figures.

\section{LITERATURE CITED}

Bladergroen, M., and Spaink, H. P. 1998. Genes and signal molecules involved in the rhizobia-leguminoseae symbiosis. Curr. Opin. Plant Biol. 1:353-359.

Canter Cremers, H. C. J., Wijffelman, C. A., Pees, E., Engels, M., Hoogerbruggen, F., Stevens, K., van Dijk, M., and Lugtenberg, B. J. J. 1988. Chromosomal nodulation genes of Rhizobium leguminosarum biovar viciae. Page 484 in: Nitrogen Fixation: Hundred Years After. H. Bothe, F. J. de Bruijn, and W. J. Newton, eds. Gustav Fisher, Stuttgart, Germany.

Chetkova, S. A., and Tikhonovich, I. A. 1986. Isolation and analysis of Rhizobium leguminosarum strains which are effective on Afghanistan peas. (In Russian.) Microbiologia 55:143-147.

Davis, E. O., Evans, I. J., and Johnston, A. W. B. 1988. Identification of nodX, a gene that allows Rhizobium leguminosarum biovar viciae strain TOM to nodulate Afghanistan peas. Mol. Gen. Genet. 212:531-535.

Dénarié, J., Debellé, F., and Promé, J. C. 1996. Rhizobium lipo chitooligosaccharide nodulation factors: Signaling molecules mediating recognition and morphogenesis. Annu. Rev. Biochem. 65:503-535.
Ditta, G., Stanfield, S., Corbin, D., and Helinski, D. R. 1980. Broad host-range DNA cloning system for gram-negative bacteria: Construction of a gene bank of Rhizobium meliloti. Proc. Natl. Acad. Sci. USA 77:7347-7351.

Djordjevic, M. A., Innes, R. W., Wijffelman, C. A., Schofield, P. R., and Rolfe, B. G. 1986. Nodulation of specific legumes is controlled by several distinct loci in Rhizobium trifolii. Plant Mol. Biol. 6:389-401.

Dowling, D. N., Samrey, U., Stanley, J., and Broughton, W. J. 1987. Cloning of Rhizobium leguminosarum genes for competitive nodulation blocking on peas. J. Bacteriol. 169:1345-1348.

Firmin, J. L., Wilson, K. E., Carlson, R. W., Davies, A. E., and Downie, J. A. 1993. Resistance to nodulation of cv Afghanistan peas is overcome by nodX which mediates an $O$-acetylation of the Rhizobium leguminosarum lipo-oligosaccharide nodulation factor. Mol. Microbiol. 10:351-360.

Hirsch, A. M., Drake, D., Jacobs, T. W., and Long, S. R. 1985. Nodules are induced on alfalfa roots by Agrobacterium tumefaciens and Rhizobium trifolii containing small segments of the Rhizobium meliloti nodulation region. J. Bacteriol. 161:223-230.

Johnston, A. W. B., Beynon, J. L., Buchanon-Wollaston, A. V., Setchell, S. M., Hirsch, P. R., and Beringer, J. E. 1978. High frequency transfer of nodulation ability between strains and species of Rhizobium. Nature (London) 276:634-636.

Josey, D. P., Beynon, J. L., Johnston, A. W. B., and Beringer, J. E. 1979. Strain identification in Rhizobium using intrinsic antibiotic resistance. J. Appl. Bacteriol. 46:343-350.

Kozik, A., Heidstra, R., Horvath, B., Kulikova, O., Tikhonovich, I., Ellis, T. H. N., van Kammen, A., Lie, T. A., and Bisseling, T. 1995. Pea lines carrying sym 1 or sym 2 can be nodulated by Rhizobium strains containing nodX; sym1 and sym2 are allelic. Plant Sci. 108:41-49.

Lewis-Henderson, W. R., and Djordjevic, M. A. 1991a. nodT, a positively acting cultivar specificity determinant controlling nodulation of Trifolium subterraneum by Rhizobium leguminosarum biovar trifolii. Plant Mol. Biol. 16:515-526.

Lewis-Henderson, W. R., and Djordjevic, M. A. 1991b. A cultivarspecific interaction between Rhizobium leguminosarum biovar trifolii and subterranean clover is controlled by nodM, other bacterial cultivar specificity genes, and a single recessive host gene. J. Bacteriol. 173: 2791-2799.

Lie, T. A. 1978. Symbiotic specialization in pea plants: The requirement of specific Rhizobium strains for peas from Afghanistan. Ann. Appl. Biol. 88:462-465.

Lie, T. A. 1981. Gene centres, a source for genetic variants in symbiotic nitrogen fixation: Host-induced ineffectivity in Pisum sativum ecotype fulvum. Plant Soil 61:125-134.

Ma, S.-W., and Iyer, V. N. 1990. New field isolates of Rhizobium leguminosarum biovar viciae that nodulate the primitive pea cultivar Afghanistan in addition to modern cultivars. Appl. Environ. Microbiol. 56:2206-2212.

Marsh, J. L., Erfle, M., and Wykes, E. J. 1984. The pIC plasmid and phage vectors with versatile cloning sites for recombinant selection by insertional inactivation. Gene 32:481-485.

Messing, J., and Vieira, J. 1982. A new pair of M13 vectors for selecting either strand of double-digest restriction fragments. Gene 19:269-276.

Ovtsyna, A. O., Geurts, R., Bisseling, T., Lugtenberg, B. J. J., Tikhonovich, I. A., and Spaink, H. P. 1998. Restriction of host range by the sym 2 allele of Afghan pea is nonspecific for the type of modification at the reducing terminus of nodulation signals. Mol. PlantMicrobe Interact. 11:418-422.

Philip-Hollingsworth, S., Orgambide, G. G., Bradford, J. J., Smith, D. K., Hollingsworth, R. I., and Dazzo, F. B. 1995. Mutation or increased copy number of nodE has no effect on the spectrum of chitolipooligosaccharide nod factors made by Rhizobium leguminosarum bv. trifolii. J. Biol. Chem. 270:20968-20977.

Rolfe, B. G., Innes, R. W., Schofield, P. R., Sargent, C. L., Kuempel, P. L., Plazinski, J., Canter Cremers, H., and Djordjevic, M. A. 1985. Plant secreted factors induce the expression of $R$. trifolii nodulation and host-range genes. Pages 79-85 in: Nitrogen Fixation Research Progress. H. J. Evans, P. J. Bottomley, and W. E. Newton, eds. Elsevier, New York.

Sanger, F., Nicklen, S., and Coulson, A. R. 1977. DNA sequencing with chain-terminating inhibitors. Proc. Natl. Acad. Sci. USA 74:54635467.

Spaink, H. P., Bloemberg, G. V., van Brussel, A. A. N., Lugtenberg, B. J. 
J., van der Drift, K. M. G. M., Haverkamp, J., and Thomas-Oates, J. E. 1995a. Host specificity of Rhizobium leguminosarum is determined by the hydrophobicity of highly unsaturated fatty acyl moieties of the nodulation factors. Mol. Plant-Microbe Interact. 8:155-164.

Spaink, H. P., Bloemberg, G. V., Wijfjes, A. H. M., Ritsema, T., Geiger, O., López-Lara, I. M., Harteveld, M., Kafetzopoulos, D., van Brussel, A. A. N., Kijne, J. W., Lugtenberg, B. J. J., van der Drift, K. M. G. M., Thomas-Oates, J. E., Potrykus, I., and Sautter, C. 1994a. The molecular basis of host-specificity in the Rhizobium leguminosarumplant interaction. Pages 91-98 in: Advances in Molecular Genetics of Plant-Microbe Interactions. M. J. Daniels, J. A. Downie, and A. E. Osbourn, eds. Kluwer Academic Pub., Dordrecht, The Netherlands.

Spaink, H. P., Wijfjes, A. H. M., and Lugtenberg, B. J. J. 1995b. Rhizobium NodI and NodJ proteins play a role in the efficiency of secretion of lipochitin oligosaccharides. J. Bacteriol. 177:6276-6281.

Spaink, H. P., Wijfjes, A. H. M., van der Drift, K. M. G. M., Haverkamp, J., Thomas-Oates, J. E., and Lugtenberg, B. J. J. 1994b. Structural identification of metabolites produced by the NodB and NodC proteins of Rhizobium leguminosarum. Mol. Microbiol. 13:821-831.

Studier, F. W., Rosenberg, A. H., Dunn, J. J., and Dubendorf, J. W. 1990. Use of T7 RNA polymerase to direct expression of cloned genes. Methods Enzymol. 185:60-89.

van Brussel, A. A. N., Planqué, K., and Quispel, A. 1977. The wall of Rhizobium leguminosarum in bacteroid and free-living forms. J. Gen. Microbiol. 101:51-56.

Winarno, R., and Lie, T. A. 1979. Competition between Rhizobium strains in nodule formation: Interaction between nodulating and nonnodulating strains. Plant Soil 51:135-142. 